\title{
Block Copolymers Containing Conjugated Polymer and Polypeptide Sequences: Synthesis and Self-Assembly of Electroactive and Photoactive Nanostructures
}

\author{
Xiangxing Kong and Samson A. Jenekhe* \\ Department of Chemical Engineering and Department of Chemistry \\ University of Washington, Seattle, Washington 98195-1750
}

\section{Supporting Information}

Synthesis of phthalimide-capped poly(9,9-dihexylfluorene-2,7-diyl) (1a). 2,2'-Bipyridine $(1.140 \mathrm{~g}, 7.2 \mathrm{mmol})$ and $\mathrm{Ni}(\mathrm{COD})_{2}(1.980 \mathrm{~g}, 7.2 \mathrm{mmol})$ were added into a flask in a glove box under nitrogen. After taking out the flask from the glove box, $1 \mathrm{~mL}$ of 1,5-cyclooctadiene (COD), $10 \mathrm{~mL}$ of anhydrous DMF and $10 \mathrm{~mL}$ of anhydrous toluene were injected with a syringe under argon. The blue solution was heated at $70{ }^{\circ} \mathrm{C}$ for $30 \mathrm{~min}$. In another three-neck flask, 2,7dibromo-9,9-dihexylfluorene (2.462 g, $5 \mathrm{mmol})$ and 4-bromobenzyl phthalimide $(316.2 \mathrm{mg}, 1$ mmol) were dissolved in $10 \mathrm{~mL}$ of dry toluene. The monomer solution was transferred into the blue catalytic solution. The reaction was stirred for 3 days under argon. The reaction mixture was poured into $200 \mathrm{~mL}$ of methanol containing $1 \mathrm{~mL}$ of concentrated $\mathrm{HCl}$. The precipitate was dried in a vacuum oven at $60{ }^{\circ} \mathrm{C}$. The PHF without the phthalimide-capping was separated by column chromatography by first washing with carbon tetrachloride, followed by THF. The light yellow phthalimide-capped PHF (1a) (0.92 g) was obtained by precipitation from methanol and dried, yield: $55 \% .{ }^{1} \mathrm{H}$ NMR $\left(200 \mathrm{MHz}, \mathrm{CDCl}_{3}\right), \delta(\mathrm{ppm}):$ 7.89-7.48 (m, Ar-H), $4.95\left(\mathrm{~s}, \mathrm{~N}-\mathrm{CH}_{2^{-}}\right.$ Ar), $2.14\left(\mathrm{~b}, \mathrm{CH}_{2}\right), 1.16\left(\mathrm{~b}, \mathrm{CH}_{2}\right), 0.82\left(\mathrm{~b}, \mathrm{CH}_{2}\right.$, and $\left.\mathrm{CH}_{3}\right)$. IR (KBr pellet), $v\left(\mathrm{~cm}^{-1}\right)$ : $3022(\mathrm{C}-\mathrm{H}$ stretching), 2924, 2851, $1772(\mathrm{C}=\mathrm{O}$ in phthalimide $), 1718(\mathrm{C}=\mathrm{O}$ in phthalimide $), 1609(\mathrm{C}=\mathrm{C}$ in 
Ar), 1456. 810. From the ${ }^{1} \mathrm{H}$ NMR spectrum, end group analysis gave that the repeat unit in 1a to be 15 based on the ratio between the integration of the methylene protons $\left(2 \times \mathrm{CH}_{2}\right)$ of the $n$ hexyl group at $2.10 \mathrm{ppm}$ and the methylene protons adjacent to phthalimide end group $\left(\mathrm{PhCH}_{2} \mathrm{~N}\right)$ at $4.95 \mathrm{ppm}$.

Synthesis of phthalimide-capped poly(9,9-dihexylfluorene-2,7-diyl) (1b). Similar procedure was followed as in 1a. Here the molar ratio between of 2,7-dibromo-9,9dihexylfluorene and 4-bromobenzyl phthalimide was controlled to be $5 \mathrm{mmol} / 0.5 \mathrm{mmol}$. A 0.98 g light yellow phthalimide-capped PHF (1b) was obtained, yield: 59\%. ${ }^{1} \mathrm{H}$ NMR (200 MHz, $\left.\mathrm{CDCl}_{3}\right), \delta(\mathrm{ppm}):$ 7.89-7.48 (m, Ar-H), 4.95 (s, N-CH2-Ar), 2.14 (b, $\left.\mathrm{CH}_{2}\right), 1.16\left(\mathrm{~b}, \mathrm{CH}_{2}\right), 0.82$ (b, $\mathrm{CH}_{2}$, and $\left.\mathrm{CH}_{3}\right)$. IR (KBr pellet), $v\left(\mathrm{~cm}^{-1}\right): 3022$ (C-H stretching), 2924, 2851, $1772(\mathrm{C}=\mathrm{O}$ in phthalimide), $1718(\mathrm{C}=\mathrm{O}$ in phthalimide $), 1609(\mathrm{C}=\mathrm{C}$ in $\mathrm{Ar}), 1456.810$. End group analysis from the ${ }^{1} \mathrm{H}$ NMR spectrum gave that the repeat unit in $\mathbf{1 b}$ to be 28 based on the ratio between the integration of the methylene protons $\left(2 \times \mathrm{CH}_{2}\right)$ of the $n$-hexyl group at $2.10 \mathrm{ppm}$ and the methylene protons adjacent to phthalimide end group $\left(\mathrm{PhCH}_{2} \mathrm{~N}\right)$ at $4.95 \mathrm{ppm}$.

Synthesis of benzylamine-capped poly(9,9-dihexylfluorene-2,7-diyl) (2a). The deprotection of $\mathbf{1 a}$ to get $\mathbf{2 a}$ was done as follows. $0.90 \mathrm{~g}$ of phthalimide-capped poly(9,9dihexylfluorene) (1a) was dissolved in $20 \mathrm{~mL}$ of THF and $1 \mathrm{~mL}$ methanol under argon. $1 \mathrm{~mL}$ of hydrazine was then injected. The mixture was refluxed for overnight. The polymer was precipitated from methanol and the white powder benzylamine-capped PHF (2a) (0.84 g) was obtained. ${ }^{1} \mathrm{H}$ NMR (200 MHz, $\left.\mathrm{CDCl}_{3}\right), \delta$ (ppm): 7.86-7.41 (m, Ar-H), 3.95 (s, N-CH $\left.-\mathrm{Ar}\right), 2.10$ (b, $\left.\mathrm{CH}_{2}\right), 1.13\left(\mathrm{~b}, \mathrm{CH}_{2}\right), 0.79$ (b, $\mathrm{CH}_{2}$ and $\left.\mathrm{CH}_{3}\right)$. IR (KBr pellet), $v\left(\mathrm{~cm}^{-1}\right):$ 3023, 2953, 2926, 2855, $1608(\mathrm{C}=\mathrm{C}$ in Ar), 1457, 812. GPC (THF, PSt standard $): M_{\mathrm{w}}=8.68 \times 10^{3}, M_{\mathrm{w}} / M_{\mathrm{n}}=2.35$. ${ }^{1} \mathrm{H}$ NMR spectrum provided that the repeat unit in $\mathbf{2 a}$ was 15 based on the ratio between the 
integration of the methylene protons $\left(2 \times \mathrm{CH}_{2}\right)$ of the $n$-hexyl group at $2.10 \mathrm{ppm}$ and the methylene protons in benzylamine end group $\left(\mathrm{CH}_{2} \mathrm{NH}_{2}\right)$ at $3.95 \mathrm{ppm}$.

\section{Synthesis of benzylamine-capped poly(9,9-dihexylfluorene-2,7-diyl) (2b). Similar}

procedure was followed as in $\mathbf{2 a}$, resulting in obtaining $0.85 \mathrm{~g}$ of $\mathbf{2} \mathbf{b}$ from $1 \mathrm{~g}$ of $\mathbf{1 b}$. ${ }^{1} \mathrm{H}$ NMR (200 MHz, $\mathrm{CDCl}_{3}$ ), $\delta$ (ppm): 7.86-7.41 (m, Ar-H), 3.95 (s, N-CH2 $\left.-\mathrm{Ar}\right), 2.10$ (b, $\left.\mathrm{CH}_{2}\right), 1.13$ (b, $\left.\mathrm{CH}_{2}\right), 0.79$ (b, $\mathrm{CH}_{2}$ and $\left.\mathrm{CH}_{3}\right)$. IR ( $\mathrm{KBr}$ pellet), $v\left(\mathrm{~cm}^{-1}\right): 3023,2953,2926,2855,1608(\mathrm{C}=\mathrm{C}$ in Ar), 1457, 812. GPC: $M_{\mathrm{w}}=2.34 \times 10^{4}, M_{\mathrm{w}} / M_{\mathrm{n}}=2.36$. End group analysis from the ${ }^{1} \mathrm{H}$ NMR spectrum gave the repeat unit in $\mathbf{2 b}$ to be 27 based on the ratio between the integration of the methylene protons $\left(2 \times \mathrm{CH}_{2}\right)$ of the $n$-hexyl group at $2.10 \mathrm{ppm}$ and the methylene protons in benzylamine end group $\left(\mathrm{CH}_{2} \mathrm{NH}_{2}\right)$ at $3.95 \mathrm{ppm}$.

Synthesis of triblock copolymer 3a. In a flame-dried flask, $240 \mathrm{mg}(0.05 \mathrm{mmol})$ of benzylamine-capped PHF (2a) and 522.2 mg of Bn-Glu NCA ( 2 mmol) were added under Ar. 10 $\mathrm{mL}$ of anhydrous THF was injected by a syringe. The mixture solution was stirred under argon for 3 days. The triblock copolymer 3a was precipitated from methanol and dried in a vacuum oven. A 515 mg product was obtained. Yield: 76\%. The block copolymer was \#\# ${ }^{1} \mathrm{H}$ NMR (200 $\left.\mathrm{MHz}, \mathrm{CDCl}_{3}\right), \delta(\mathrm{ppm}):$ 7.85-7.30 (m, Ar-H), $5.03\left(\mathrm{~s}, \mathrm{OCH}_{2} \mathrm{Ph}\right), 4.49\left(\mathrm{~s}, \mathrm{CONH}_{2} \mathrm{CH}_{2} \mathrm{Ph}\right) ; 3.93$ (b, $\mathrm{CONH}), 2.6-2.12\left(\mathrm{~m}, \mathrm{CH}_{2} \mathrm{CH}_{2}\right.$, and $\left.\mathrm{CH}_{2}\right) ; 1.20\left(\mathrm{~b}, \mathrm{CH}_{2}\right), 0.79\left(\mathrm{~b}, \mathrm{CH}_{2}\right.$, and $\left.\mathrm{CH}_{3}\right)$. FTIR $(\mathrm{KBr}$ pellet), $v\left(\mathrm{~cm}^{-1}\right)$ : 3291 (N-H stretch), 3033, 2928, 2857, 1734, 1653 (amide I band), 1548 (amide II band), 813. GPC: $M_{\mathrm{w}}=1.63 \times 10^{4}, M_{\mathrm{w}} / M_{\mathrm{n}}=2.32$. End group analysis of the block copolymer by ${ }^{1} \mathrm{H}$ NMR (integration of the methylene protons in $\mathrm{COOCH}_{2} \mathrm{Ph}$ of PBLG at $5.03 \mathrm{ppm}$ relative to the methylene protons $\left(6 \times \mathrm{CH}_{2}\right)$ in n-hexyl group at $\left.1.20 \mathrm{ppm}\right)$ showed that the total PBLG repeat units in block copolymer 3a was 46 and thus each PBLG block in 3a had a repeat unit of 23. 
Synthesis of block copolymer 3b. Similar procedure was followed as in 3a. A $540 \mathrm{mg}$ triblock copolymer 3b was obtained. Yield: $60 \% .{ }^{1} \mathrm{H}$ NMR (200 MHz, $\left.\mathrm{CDCl}_{3}\right), \delta(\mathrm{ppm}): 7.85-$ $7.30(\mathrm{~m}, \mathrm{Ar}-\mathrm{H}), 5.03\left(\mathrm{~s}, \mathrm{OCH}_{2} \mathrm{Ph}\right), 4.49\left(\mathrm{~s}, \mathrm{CONH}_{2} \mathrm{CH}_{2} \mathrm{Ph}\right) ; 3.93(\mathrm{~b}, \mathrm{CONH}), 2.6-2.12(\mathrm{~m}$, $\mathrm{CH}_{2} \mathrm{CH}_{2}$, and $\left.\mathrm{CH}_{2}\right) ; 1.20$ (b, $\left.\mathrm{CH}_{2}\right), 0.79$ (b, $\mathrm{CH}_{2}$, and $\mathrm{CH}_{3}$ ). FTIR ( $\mathrm{KBr}$ pellet), $v\left(\mathrm{~cm}^{-1}\right): 3291$ (N-H stretch), 3033, 2928, 2857, 1734, 1653 (amide I band), 1630, 1548, 813. GPC: $M_{\mathrm{w}}=3.27$ $\times 10^{4}, M_{\mathrm{w}} / M_{\mathrm{n}}=2.10$. End group analysis of the block copolymer $(\mathbf{3 b})$ by ${ }^{1} \mathrm{H}$ NMR (integration of the methylene protons in $\mathrm{COOCH}_{2} \mathrm{Ph}$ of $\mathrm{PBLG}$ at $5.03 \mathrm{ppm}$ relative to the methylene protons $\left(6 \times \mathrm{CH}_{2}\right)$ in n-hexyl group at $\left.1.20 \mathrm{ppm}\right)$ showed that the total PBLG repeat units in block copolymer $\mathbf{3 b}$ was 32 and thus each PBLG block in $\mathbf{3 b}$ had a repeat unit of 16.

Characterization. FTIR spectra were recorded with a Bruker Vector 33 Fourier transform infrared spectrophotometer. ${ }^{1} \mathrm{H}$ NMR spectra were carried out at $200 \mathrm{MHz}$ on a Bruker dpx200 spectrometer. UV-Vis absorption spectra were obtained on a Perkin-Elmer Lamda 900 spectrophotometer. Photoluminescence (PL) studies were done by using a Photon Technology International Inc. (PTI) QM-2001-4 steady state spectrofluorometer. CD spectra of the polymer films were recorded by Jasco 720 circular dichroism spectrophotometer. GPC analysis of the polymers was carried out using Shodex GPC gel columns, a Waters $150 \mathrm{C}$ RI Detector at $30^{\circ} \mathrm{C}$ with THF solvent and a flow rate of $0.5 \mathrm{ml} / \mathrm{min}$. The molecular weight was calibrated by using polystyrene standards. X-ray diffraction powder patterns of the polymers were measured using a Philips PW 1830 X-ray diffractometer. The X-ray beam was a nickel-filtered $\mathrm{Cu} K_{\alpha}(\lambda=1.5418$ Å) radiation. Data was collected from $3^{\circ}$ to $30^{\circ}$ at a scan rate of $0.5 \% \mathrm{~min}$.

AFM measurements were performed with a Nanoscope III microscope operated in tapping mode at room temperature in air, using micro-fabricated cantilevers (spring constant of $30 \mathrm{~N} / \mathrm{m}$ ). The amplitude images were recorded on the $256 \times 256$ pixels. Thin film deposition was carried 
out as follows: a $1 \%(\mathrm{w} / \mathrm{v})$ block copolymer in a mixture of TFA/chloroform $(\mathrm{v} / \mathrm{v}=3 / 97$ or 30/70) was deposited onto freshly cleaned mica with a pipette and left to evaporate for up to $12 \mathrm{~h}$ in a solvent-saturated atmosphere.

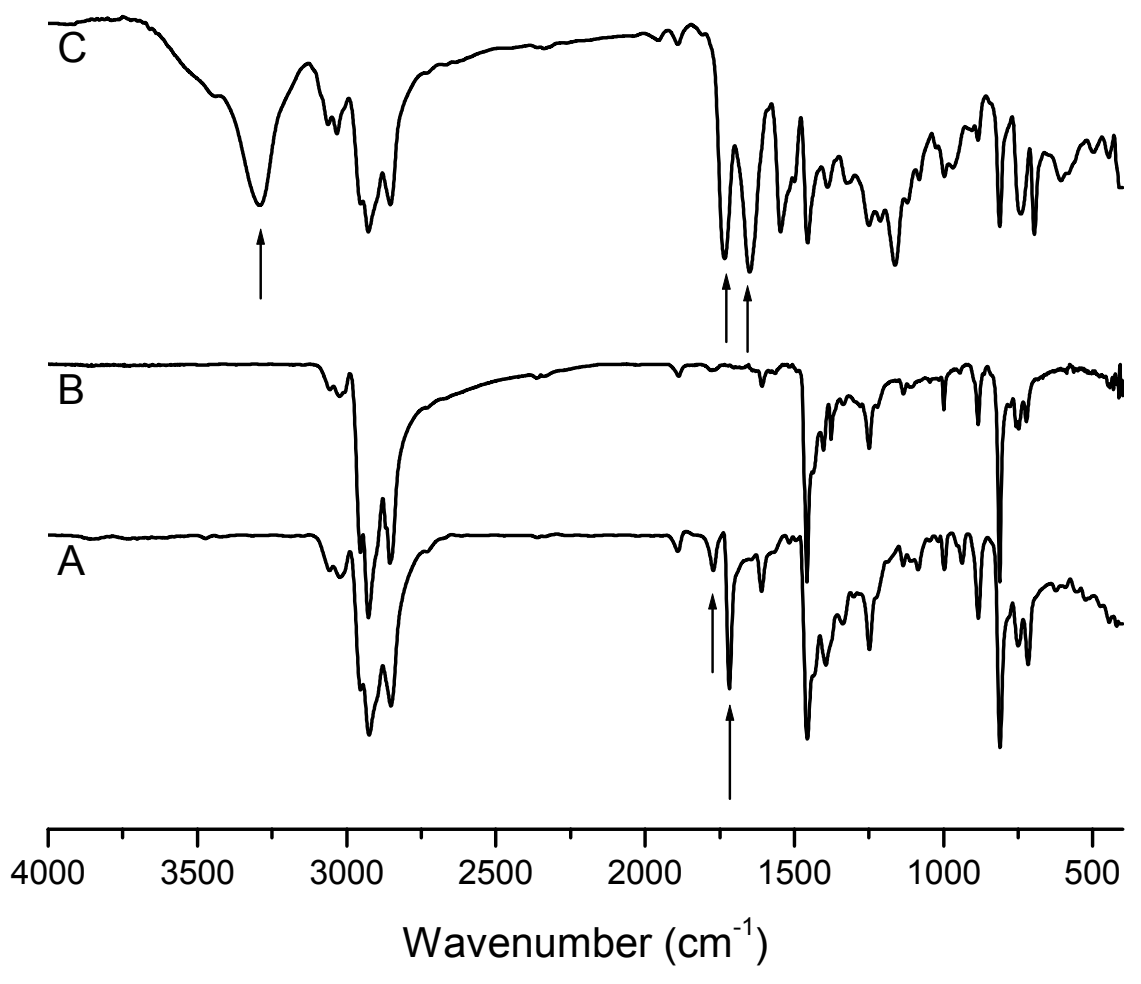

Figure S1. FTIR spectra of (A) phthalimide-capped polyfluorene 1b, (B) amino-capped polyfluorene macroinitiator $\mathbf{2 b}$ and (C) block copolymer $\mathbf{3 b}$. 


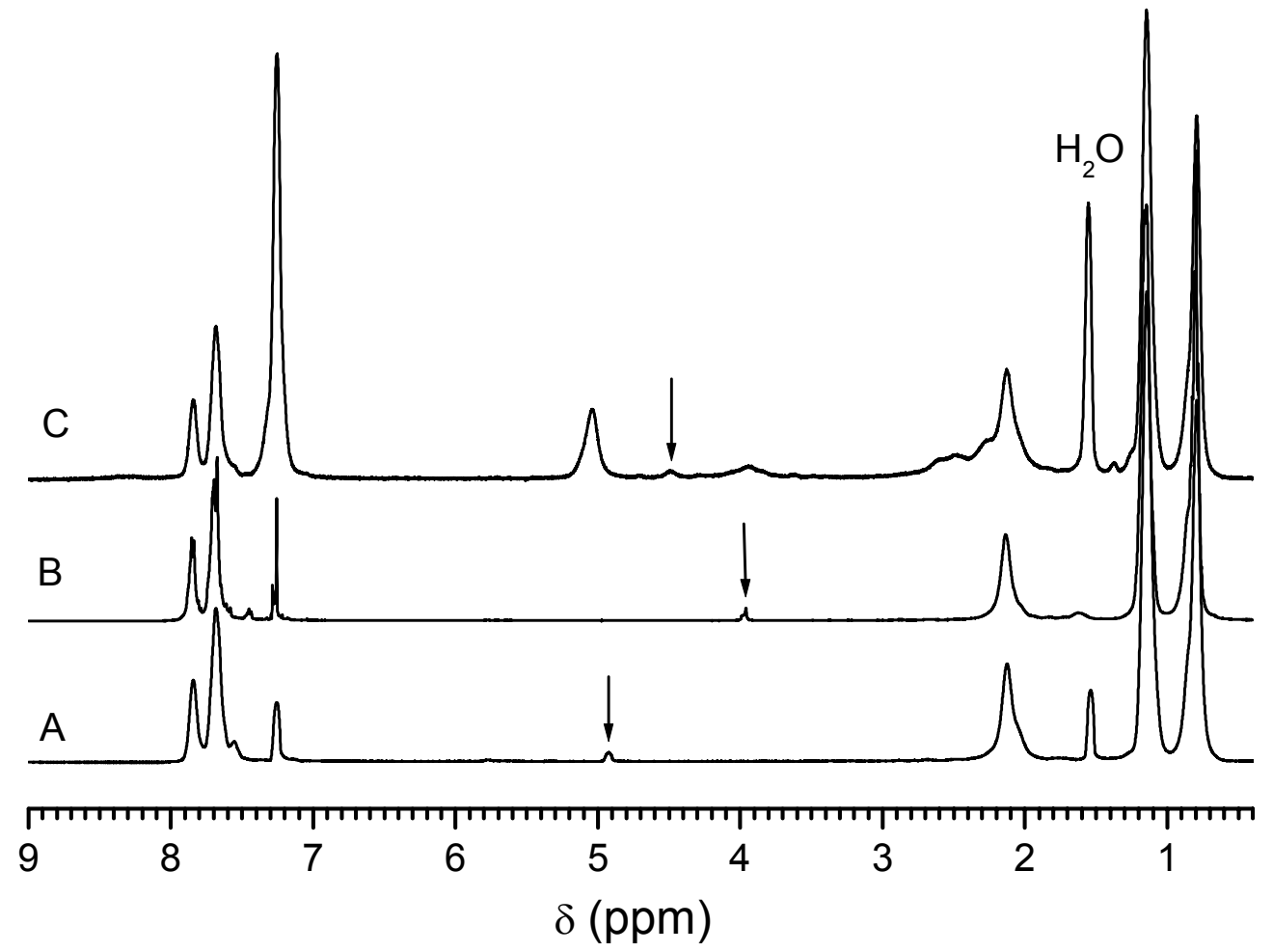

Figure S2. ${ }^{1} \mathrm{H}$ NMR spectra of (A) phthalimide-capped polyfluorene 1b, (B) benzylaminecapped polyfluorene macroinitiator $\mathbf{2 b}$, and (C) block copolymer $\mathbf{3 b}$. 


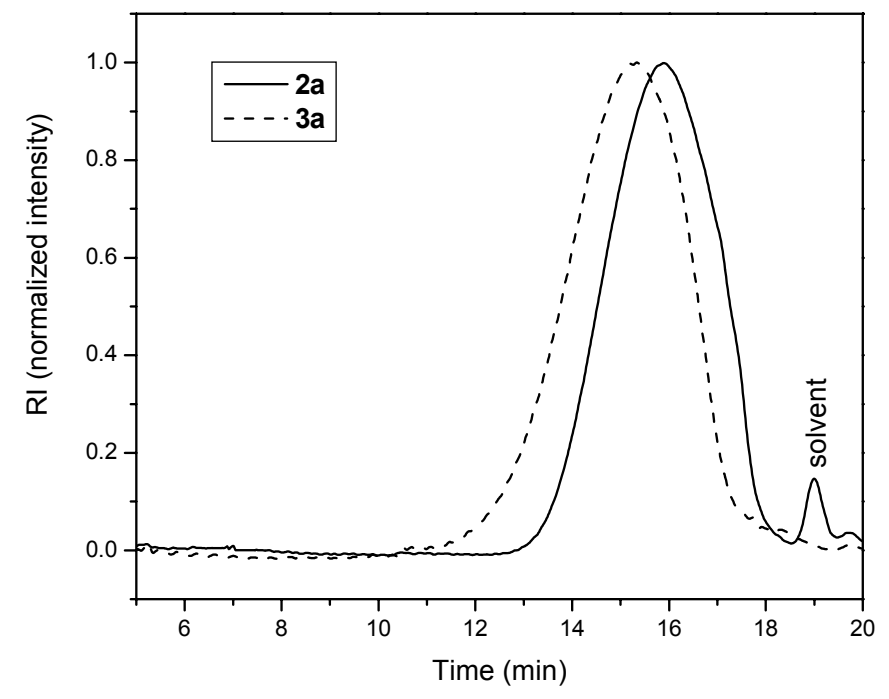

Figure S3. GPC curves of macroinitiators 2a and block copolymers 3a. 


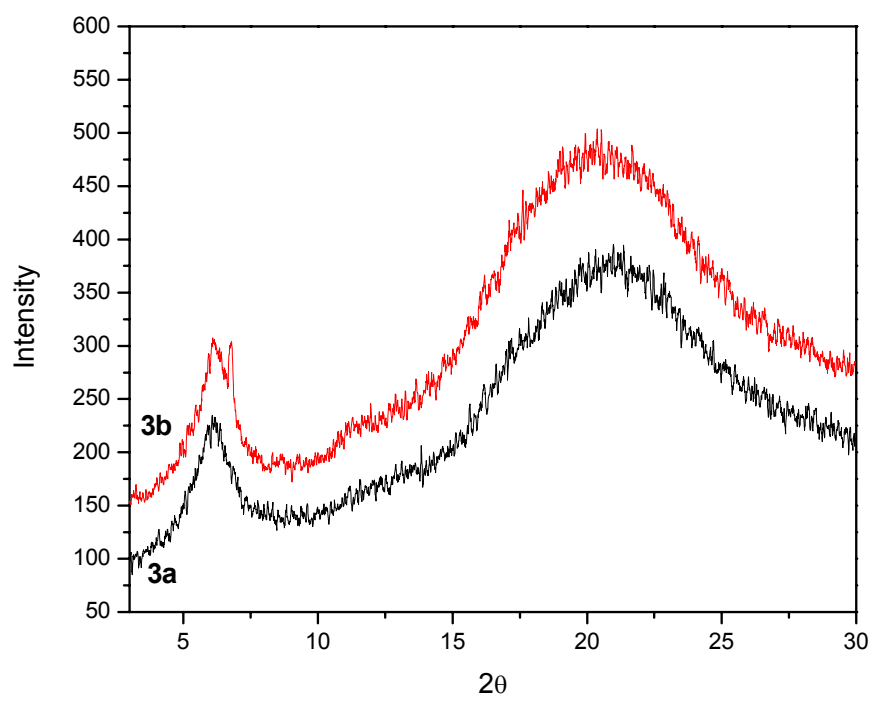

Figure S4. XRD patterns of block copolymers 3a and $\mathbf{3 b}$ after annealing in the vapor of $\mathrm{TFA} / \mathrm{CHCl}_{3}(3 / 97, \mathrm{v} / \mathrm{v})$. 


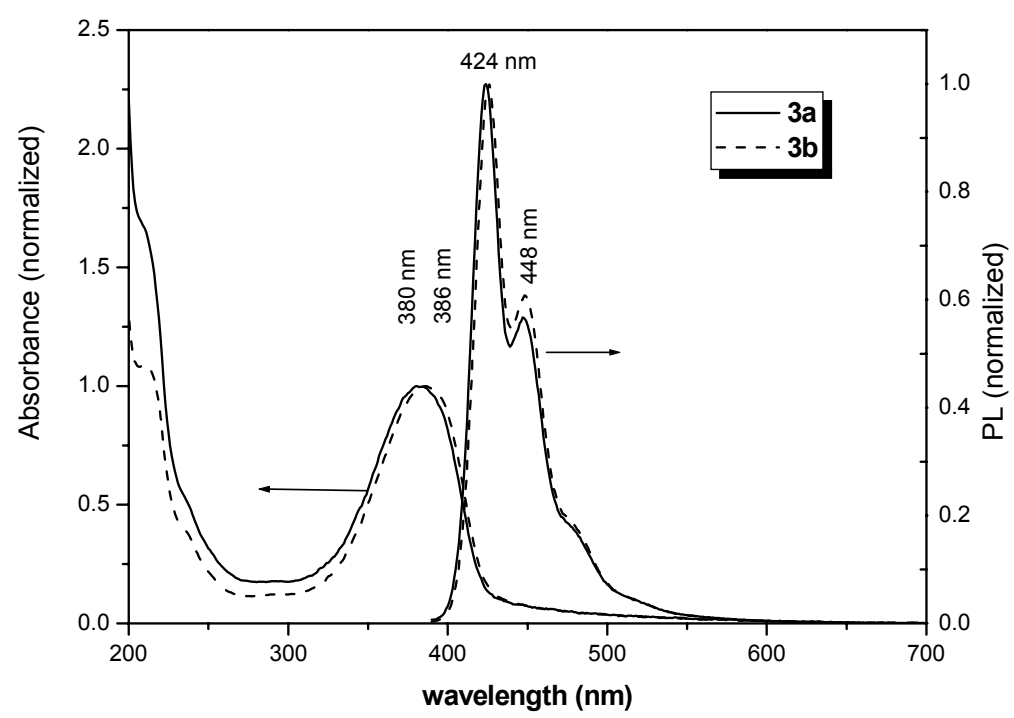

Figure S5. UV and PL spectra of spin coated films of 3a and $\mathbf{3 b}$ from $1 \% \mathrm{CHCl}_{3}$ solution.

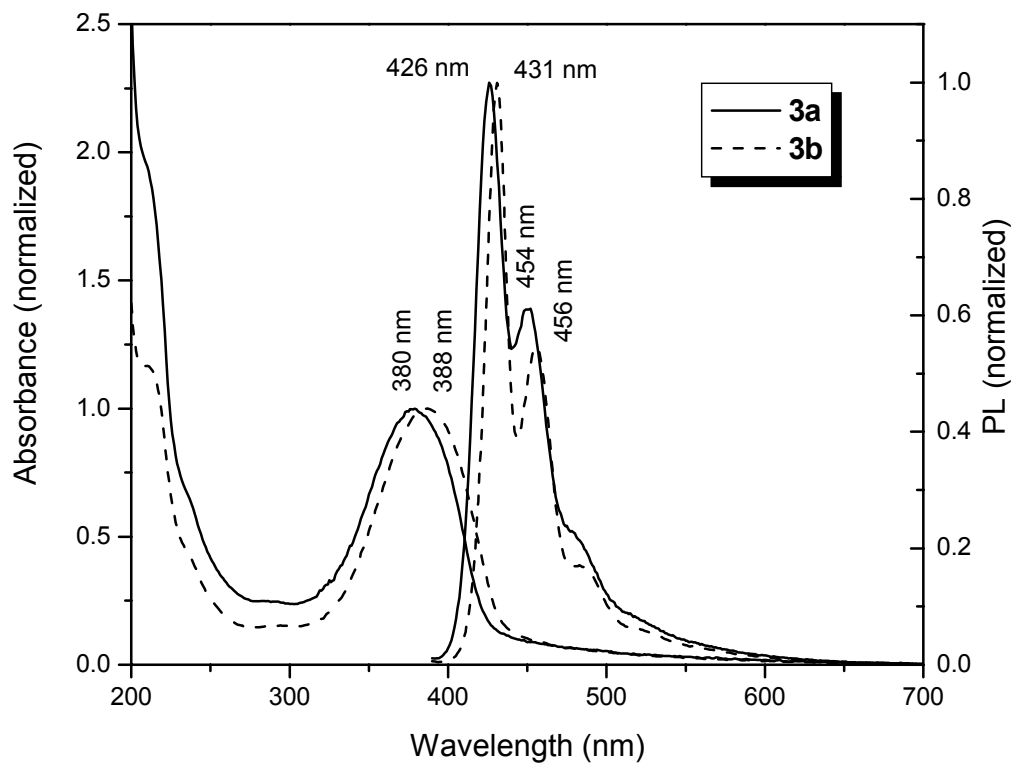

Figure S6. UV and PL spectra of spin coated films of $\mathbf{3 a}$ and $\mathbf{3 b}$ from $1 \% \mathrm{CHCl}_{3}$ solution after annealing in the vapor of TFA/CHCl $3(3 / 97, \mathrm{v} / \mathrm{v})$. 


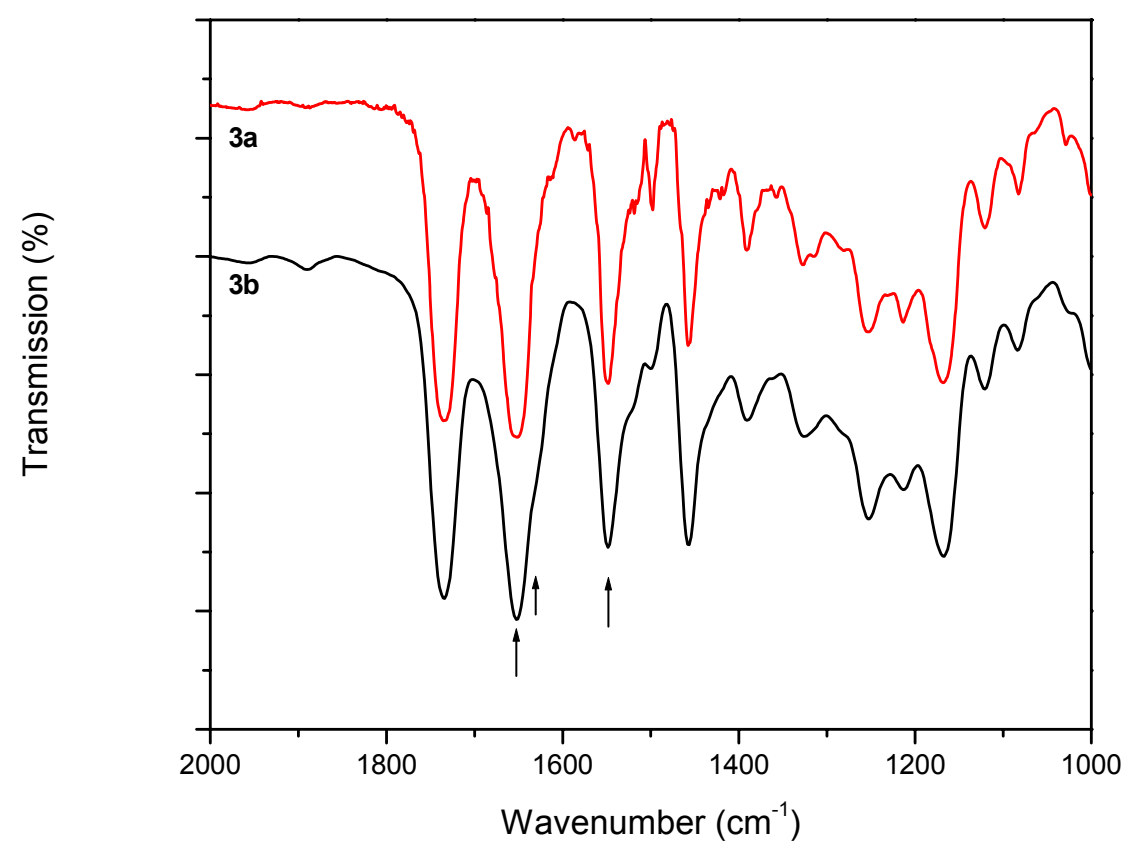

Figure S7. FT-IR spectra of block copolymer 3a and 3b films cast on KBr pellets. 

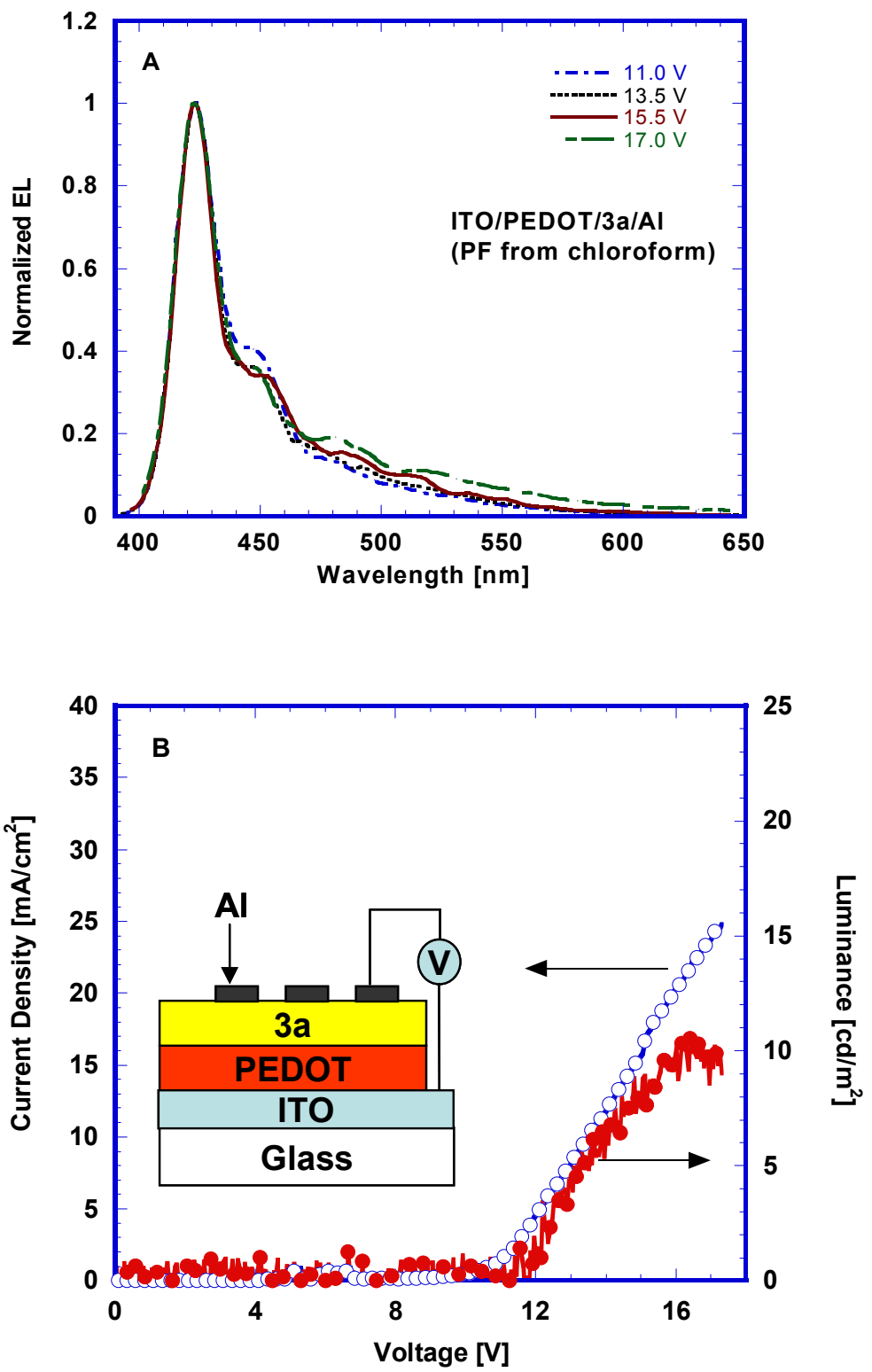

Figure S8. Electroluminescence spectra (A) and current-luminance-voltage characteristics (B) of an ITO/PEDOT/3a $(60 \mathrm{~nm}) / \mathrm{Al}$ light-emitting diode. 


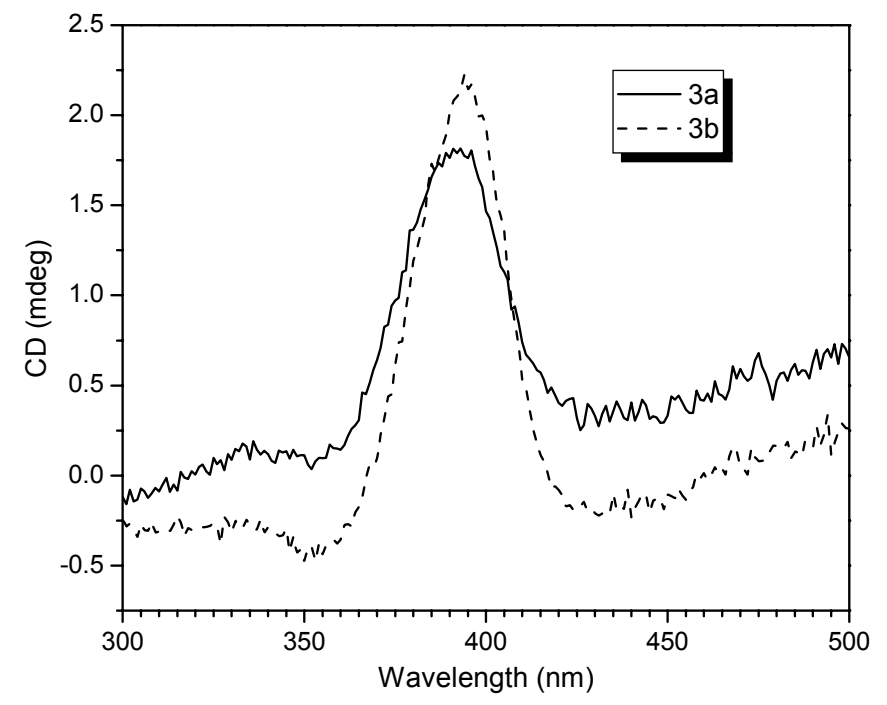

Figure S9. CD spectra of spin casted block copolymer films (annealed in the $\mathrm{TFA} / \mathrm{CHCl}_{3}(3 / 97)$ solvent vapor overnight). Thickness of the film: $90 \mathrm{~nm}$ for $\mathbf{3 a}$ and $110 \mathrm{~nm}$ for $\mathbf{3 b}$. 